Running Head: SOCIAL MOTIVE EXPECTATIONS AND CONCESSION TIMING EFFECT

Social Motive Expectations and the Concession Timing Effect

\author{
Seungwoo Kwon \\ Korea University Business School \\ Korea University \\ 1, 5-ga, Anam-Dong, Sungbuk-Gu, \\ Seoul Korea 136-701 \\ Phone: $+82-2-3290-2604$ \\ Fax: +82-2-922-7220 \\ E-mail: winwin@korea.ac.kr \\ Laurie R. Weingart \\ David A. Tepper School of Business \\ Carnegie Mellon University \\ 236A Posner Hall \\ Pittsburgh, PA 15217 \\ Phone: 412-286-7585 \\ Fax: 412-268-6920 \\ E-mail: weingart@cmu.edu
}

Paper submitted: August 24, 2005 


\begin{abstract}
It has been shown that concession timing can influence a negotiator's satisfaction with and judgment of the negotiation partner, the quality of the object, and the agreed upon price (Kwon \& Weingart, 2004). This study tested whether the concession timing effect holds when a negotiator believes the other party is cooperatively oriented. The results suggest that a negotiator's belief about the other party's social motive overrides the concession timing effect. Specifically, if the other party was believed to be cooperative, negotiators did not feel dissatisfied with the outcome or the negotiating partner, did not evaluate the quality and value of the object as being low, and perceived the negotiating partner as credible, even when the other party made early concessions.
\end{abstract}




\section{Social Motive Expectations and the Concession Timing Effect}

Negotiators tend to evaluate the quality of their own performance and make judgments about their outcomes, and these judgments influence their approach to future negotiations with the same and other partners (Thompson, Peterson, \& Kray, 1995). Various reference points are used to judge the quality of a potential negotiated outcome (White \& Neale, 1994; White, Valley, Bazerman, Neale, \& Peck, 1994): for example, asking price (Milgrom \& Roberts, 1986), perceptions of the negotiation partner's outcome (Thompson, Valley, \& Kramer, 1995), and the timing of the partner's concessions (Galinsky, Seiden, Kim, \& Medvec, 2002; Kwon \& Weingart, 2004).

The timing of the other party's concession can be used to infer the value of the object under consideration, the credibility of the other party, and the quality of the agreement in singleissue negotiations of transactions (Galinsky et al., 2002; Kwon \& Weingart, 2004). Research examining immediate, gradual, and delayed concessions found that when the other party immediately accepted the focal negotiator's offer, the negotiator felt least satisfied with the outcome. Galinsky et al. (2002) showed that an immediate concession from the other party triggered counterfactual thinking, "I could have done better," leading individuals who perform objectively better to feel worse than those whom they outperformed (Markman, Gavanski, Sherman, \& McMullen, 1993; Medvec, Madey, \& Gilovich, 1995). Kwon and Weingart (2004) reported similar results. When the other party made gradual concessions, negotiators were more satisfied with the negotiation partner and perceived him or her as more credible. A negotiating partner's delayed concession making led negotiators to report high levels of satisfaction with the outcome and to estimate the quality and value of the object to be high. Kwon and Weingart (2004) explained that the salience and unexpectedness of an immediate concession by a 
negotiation partner intensifies the reactive devaluation (Curhan, Neale, \& Ross, 2004; Ross, 1995; Ross \& Stillinger, 1991) effect of a concession, resulting in a buyer's belief that the object is worth less than initially believed and buyer's dissatisfaction with the outcome. They labeled this the "concession timing effect".

Important to the generalizability of this research is that both studies examined the concession timing effect in a single-issue, distributive bargaining context - the purchase of a car and the purchase of a Persian rug. In addition, participants were strangers to one another with no information about the other party's reputation or motives. Single-issue negotiations between two parties with no past or expected future relationship represent the prototypical distributive bargaining context (Raiffa, 1982) in which participants are expected to engage competitive negotiation strategies and tactics. Competitive, or distributive, tactics in single-issue negotiations focus on withholding information, large opening offers, and resistance to yielding (Lewicki, Barry, Saunders, \& Minton, 2003). In that single-issue negotiations among strangers cue competitive behavior, negotiators entering these situations are likely to expect the other party to be individualistically (focused on maximizing own outcome) or competitively (focused on maximizing own outcome at the expense of the other party) motivated. ${ }^{1}$ This expectation provides the context within which the other party's concession behavior is interpreted. Thus, the other party's concessions are likely to be interpreted as indirectly self-serving. That is, concessions, especially immediate ones, will be interpreted as signaling a defective or overpriced object that the other party is trying to unload rather than a conciliatory move designed to aid the focal negotiator.

The current study directly examines a negotiator's expectations of the other party's motives to determine whether the concession timing effect is limited to purely competitive 
situations. Will a negotiator be suspicious when an immediate concession is made by a negotiator believed to be cooperatively motivated? Judgment about the other party's underlying motivation may play a crucial role in perceiving and evaluating the negotiation process and outcomes.

We test whether the concession timing effect holds when negotiators believe the other party is cooperatively motivated. Cooperative expectations of the other's orientation might occur in negotiations with friends or benevolent business partners (i.e., when the relationship is important). When the other party is assumed to be cooperative, a negotiator might make different attributions regarding concession timing than when the other party is not assumed to be cooperative. That is, the concession timing effect might be stronger in situations marked by fear of exploitation. In this study, we explore the possibility that a belief about the other party's underlying motivation will moderate the effect of concession timing on the negotiation perception. In addition, interpreting the other party's underlying motivation will affect how a negotiator makes attributions and perceives the negotiation outcome, object, and the negotiation partner (see Figure 1).

\section{Social Motives}

Social motives refer to preferences for certain patterns of outcomes for oneself and others (Deutsch 1949, 1969, 1973; McClintock, 1978; Messick \& McClintock, 1968). Negotiators with cooperative motives tend to work toward a goal of maximizing both own and others' outcomes and minimizing differences between outcomes for themselves and others. In contrast, negotiators with individualistic motives tend to maximize their own outcomes regardless of other's outcome. Negotiators with competitive motives tend to maximize their own outcomes relative to others' outcomes, seeking relative advantage over others. Social motives may be driven by situational 
demands or rooted in individual differences and have been shown to influence the use of tactical behavior and quality of joint agreements (see De Dreu, Weingart, \& Kwon, 2000 for a metaanalytic review).

Social motives should also influence the way negotiators pursue individual gain. In a single-issue, distributive negotiation (as the one studied here), cooperative negotiators might stop negotiating as soon as they reach a minimally acceptable agreement, because further gain for one person means a loss for the other person (Weingart, Bennett, \& Brett, 1993). In a similar negotiation, individualistic negotiators and competitive negotiators might attempt to improve their own outcome at the expense of other's outcome even after reaching a potentially acceptable agreement (Weingart et al., 1993). Thus cooperators will attempt to claim less value than will individualistic negotiators. People negotiating against others who are known to be cooperative versus individualistic should thus have different expectations about how that person should negotiate and what their behavior implies.

\section{Expectations about the Other Party's Social Motive}

Beliefs about a negotiation opponent's social motive can come from a variety of sources: one’s own social motives (Kelley \& Stahelski, 1970; Kuhlman \& Wimberley, 1976), past cooperative experiences with the other party (Van Lange, Otten, De Bruin, \& Joireman, 1997), or that person's reputation (Tinsley, O’Connor, \& Sullivan, 2001). Thus, negotiators may draw from a variety of available information as they form impressions of the negotiation and the negotiating partner. In this study, one negotiator is informed of the other's social motive by the experimenter prior to the negotiation and is expected to alter his/her attributions of the other party's behavior accordingly. 
Prior research has shown that people tend to trust others they expect to be cooperatively rather than individualistically or competitively motivated (e.g., De Cremer, Snyder, \& DeWitte, 2001; De Dreu, Giebels, \& Van de Vliert, 1998; Pruitt \& Kimmel, 1977; Van Kleef, De Dreu, \& Manstead, 2005). We expect that a negotiator's belief about the other party's social motive will also affect other perceptions of the negotiation. In this study, we investigate whether a negotiator perceives or evaluates the other party's unilateral concession making differently according to his or her expectations about the other party's social motive. Recent research on reactive devaluation in negotiation shows that the other party's reputation as being fair was not enough to overcome an individual's tendency to devalue offers made by the other party (Lepper, Ross, Ward, \& Tsai, 2002). We argue that expectation of a cooperative social motive provides more direct information about the intentions of the other party and thus should be more likely to mitigate a reactive devaluation response.

Expectations about the other party's social motive are important in a negotiation because social motives drive behavior (De Dreu et al., 2000). Therefore, when negotiators believe their partners have a cooperative social motive, they should expect cooperative behavior from the other party. Thus, the negotiation partner's concession behavior is likely to be interpreted as cooperative (regardless of the timing of the concession) and the concession will not negatively influence the negotiator's perceptions of the negotiated outcome (in terms of satisfaction, object quality assessment, and outcome value estimation) and partner (in terms of satisfaction and perceived credibility). On the other hand, when negotiators believe the other party has an individualistic social motive, they expect the other party is trying to maximize individual interest, and the other party's unilateral concession will not be interpreted as a cooperative behavior. This will result in negative perceptions of the negotiated outcome and the negotiation 
partner because negotiators will assume the other party is trying to take advantage of them in some way.

Hypothesis 1. A negotiator will evaluate the negotiation more positively in response to other party's unilateral concession when he or she believes the other party has a cooperative social motive in contrast to an individualistic social motive.

\section{Attributions}

Social motive should influence how a negotiator makes attributions in a negotiation. If negotiators believe the other party has an individualistic social motive, they will tend to find a negative reason for the other party's unilateral concession making; they may, for example, attribute such behavior to an initially overpriced object. However, negotiators who believe the other party has a cooperative social motive will be unlikely to attribute the other party's unilateral concession to the lesser true value of the object. Instead, they will tend to attribute the partner's unilateral concessions to the partner's cooperative social motive or disposition. As a result, they will be satisfied with the outcome and partner.

Hypothesis 2. Compared with negotiators who believe the other party has an individualistic social motive, negotiators who believe the other party has a cooperative social motive will be less likely to attribute the negotiation partner's unilateral concession to the lesser value of the object and more likely to attribute it to the other's disposition.

\section{Trust and Monitoring}

When an individual believes the other party is behaving honestly, he or she does not need to thoroughly monitor the other party (Yamagishi, 1986). That is, a trusting negotiator believes the other party will not exploit him or her and therefore will not be suspicious of the other party's 
behavior. When the outcome is a potentially acceptable agreement, the trusting negotiator is less likely to reflect on and analyze the negotiation process or the negotiation partner's concession patterns. As a corollary, we expect that a negotiator who believes the other party has a cooperative social motive will be satisfied with the negotiated outcome and will not be suspicious of the quality of the object of the negotiation, even if the other party concedes immediately.

In contrast, when the other party is believed to have an individualistic social motive, the focal negotiator needs to monitor the other party thoroughly in order to minimize the other's opportunistic behavior (Williamson, 1985). Furthermore, the negotiator will reflect on the negotiation process and analyze the other party's concession patterns even after the deal is closed. Individualists tend to show cooperative behavior only if they can benefit in the long run by doing so (i.e., they demonstrate instrumental concern) (Pruitt \& Rubin, 1986). In a one-shot distributive negotiation, however, individualistically-oriented individuals have no reason to be cooperative. Therefore, negotiators who believe that that the other party has an individualistic orientation will be more suspicious about the other party's motives for concession making. The negotiator is likely to think that the other party did not lose anything of real value. Scripts

There are other mechanisms through which the other party's concessionary behavior (including even an immediate concession) can be interpreted as cooperative. Individuals may have a different script for negotiating with a person with whom they perceive to have a cooperative social motive or are in close relationship. A script is a hypothesized cognitive structure (Abelson, 1981). For example, people have restaurant scripts. They know the order of events and what they are expected to do in a restaurant. People also have more specific scripts 
for fast food restaurants and more upscale restaurants. Similarly, negotiators have expectations about what will happen in a negotiation. Some research suggests that people have scripts for negotiating with friends or people in close relationships (i.e., cooperative others) (Halpern, 1996, 1997a). Negotiators in a close relationship begin with less demanding initial offers (Halpern, 1994, 1997a, 1997b; Schoeninger \& Wood, 1969) and reach agreements more quickly (Schoeninger \& Wood, 1969). In addition, they make early concessions to each other in order to maintain the relationship and tend to reach sub-optimal agreements (Fry, Firestone, \& Williams, 1983).

Negotiators may have specific negotiation scripts depending on whether the other party is cooperatively or individualistically oriented. This suggests that their expectations about the negotiation process will vary depending on their expectations regarding the other party's social motive. In a negotiation with an individualistically oriented person, negotiators do not expect immediate concession making from the other party. If people have social scripts that lead them to expect short cooperative negotiations with a cooperatively-oriented other, then negotiators will not be surprised by an immediate concession when they believe that the concession-maker is cooperatively disposed. Furthermore, the negotiator will not be suspicious of the quality of the object, will not believe he or she overpaid, and thus, the negotiation outcome be perceived as a success rather than a failure by the negotiator.

Hypothesis 3. Concession timing and the negotiation partner's expected social motive will interact to influence negotiator perceptions.

H3a. When a negotiator expects the other party to have an individualistic social motive, the negotiator will evaluate the negotiation more negatively if the other party immediately concedes rather than if the other party concedes gradually or with a delay. 
H3b. When a negotiator expects the other party to have a cooperative social motive, the negotiator will not evaluate the negotiation more negatively if the other party concedes immediately instead of conceding gradually or with a delay.

Method

\section{Participants and Design}

Eighty-eight undergraduate students enrolled in introductory courses in the management sciences participated in the experiment. Participants received extra course credit in exchange for their participation. The experiment design was 2 X 3 factorial, with belief about the other party's social motive (cooperative vs. individualistic) and concession timing (immediate, gradual, and delayed) as between-subjects variables.

\section{Negotiation Task}

Pairs of participants, each individual taking the role of buyer or seller, negotiated the price of a used car. Since there was only one issue in the task (i.e., price), the negotiation was distributive. All experimental subjects were given the role of buyer; the role of seller was played by a confederate. The buyer (experimental subject) was told they were participating in a study of ultimatum bargaining and that they should offer $\$ 9500$ for the used car and should not concede during the negotiation. The confederates, four (male) students hired from the drama department, were trained to exhibit consistent concession patterns depending on the experimental condition (immediate, gradual, or delayed). However, the seller eventually accepted the buyer's asking price, regardless of the experimental condition.

\section{Manipulations}

Concession timing. In the immediate concession condition, the (confederate) seller accepted the buyer's asking price as soon as the buyer proposed the reduced price. In the gradual concession condition, the seller made a concession every three minutes, for a total of 3 
concessions. In the delayed concession condition, the seller waited 9 minutes without making any concessions, and then accepted the buyer's offer. The seller was able to control his pace by looking at a clock placed next to the table. In that the buyer (the subject) was instructed to offer $\$ 9500$ and not to concede throughout the negotiation, the agreed-upon price was the same across all conditions.

Social motive expectation. Participants were asked to respond to a social motive questionnaire after reading the instructions for the negotiation. Prior to negotiating, participants were provided a completed questionnaire, said to have been completed by the other party. In the cooperative social motive condition, participants were shown a cooperative profile and were informed that the other party was cooperatively motivated. In the individualistic condition, participants were shown the individualistic profile in the same manner.

Social motive was (allegedly) assessed using a series of decomposed games (Messick \& McClintock, 1968) that involve making choices among combinations of outcomes for oneself and another person. In our questionnaire, participants were asked to distribute resources between themselves and the negotiation partner they were about to face (in the original measure, the other is assumed to be a hypothetical other, and thus the measure tapped social value orientation, the individual difference component of one's social motive).

\section{Procedure}

The subject (buyer) and confederate (seller) were instructed to negotiate for a used car. The subject was taken to an adjacent room to read the instructions privately. Both subject and confederate read basic information about the negotiation object (condition of the car, bluebook price, etc.). The subject then filled out the pre-negotiation questionnaire (measuring perceptions of the worth of the car) and responded to the social motives questions. 
After verifying that the subject had finished the questionnaire, the subject received "confidential" information that the experimenter was testing the effect of an ultimatum offer on the other party (the seller), and were told they had to start with their target price and continue asking for that price throughout the negotiation. They were asked to justify why the car should be $\$ 9,500$ and keep offering $\$ 9,500$. This was to ensure that the confederate's concession was unilateral and that agreed-upon price was the same across all conditions.

We then asked the subject to spend a few more minutes to develop a plan or strategy for the negotiation, after which the subject was shown the confederate's social motive response sheet. Subjects were asked to use this information to devise a strategy for the negotiation. The subject was also told that his or her own social motive response would not be shown to the other party. This was to ensure that the subject did not try to second-guess the other party when developing his or her own strategy. We asked the confederate to finish planning in the next few minutes in a voice loud enough to be overheard by the subject. Then, the subject was led to the original laboratory.

The participants were introduced and informed that the negotiation would be videotaped. Upon completing the negotiation, they responded to a post-experimental questionnaire. Subjects were then debriefed and asked not to discuss the study with other potential participants.

Measures

Own attribution. Participants were provided with and asked to choose among five alternative explanations for why the seller conceded: 1 . The seller is busy; 2 . I (the buyer) did a good job in the negotiation; 3 . The object (car) is worth less money; 4 . The seller's personality; 5. The seller is a bad negotiator. 
Outcome perceptions. Two items measured the buyer's satisfaction with the negotiated outcome $($ alpha $=.56)$ : "How satisfied are you with your agreement?" $(1=$ very dissatisfied to 7 $=\underline{\text { very satisfied }})$ and "Would you tell your friend that it was a good deal?" $(1=\underline{\text { definitely would }}$ not to $7=$ definitely would). The estimated quality of the object was measured with two items

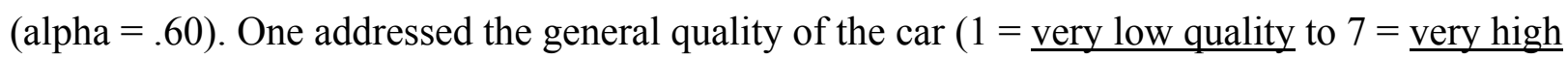
quality); the other asked about the participants' expectations that the buyer would have problems with the car after the sale $(1=\underline{\text { never }}$ to $7=\underline{\text { always }})$. To measure the estimated value of the object, participants were asked to estimate the value of the car in dollars. They were first asked to estimate the car's worth based on the bluebook price and the information from the used car ad. They then estimated the car's worth again after the negotiation.

Person perceptions. Two items assessed the buyer's satisfaction with the negotiation partner $($ alpha $=.86)$ : "Would you be willing to negotiate with the same partner again?" $(1=\underline{\text { No, }}$

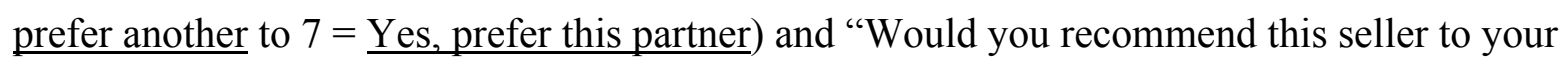
friend for another negotiation?" $(1=\underline{\text { definitely would not to } 7=\text { definitely would })}$. The credibility of the seller was measured using two items $(1=\underline{\text { strongly disagree to } 7=\underline{\text { strongly }}}$ agree). The first asked whether the seller provided complete information about the car. The second was modified from Cook and Wall's (1980) item measuring faith in management ("The seller was quite prepared to gain advantage by deceiving me."); it was reverse-scored. Internal consistency reliability was somewhat low at .52 , but using only one item did not improve the construct's relationship with other variables, so the two-item scale was retained. 
Results

\section{Manipulation Checks}

Concession timing. In the post-negotiation questionnaire participants were asked to choose between three descriptions of the timing of concessions: immediate, gradual, and delayed. Ninety-three, 78 , and $90 \%$ of the participants in the immediate, gradual, and delayed concession conditions respectively responded correctly $\left(\chi^{2}(4, \underline{N}=88)=118.28, \underline{p}<.001\right)$. Hypothesis tests were conducted with and without responses from participants who incorrectly identified the type of concession timing. Results did not differ; therefore, the full dataset was used for the analyses.

Social motive. In the post-negotiation questionnaire, participants were asked to report the social motive of the other party $(1=\underline{\text { cooperative }}$ to $5=\underline{\text { uncooperative }})$. Participants who were told that the other party had a cooperative social motive reported that the other party was more cooperative $(\mathrm{M}=1.53, \mathrm{SD}=.73, \underline{\mathrm{n}}=45)$ than did participants who were told that the other party had an individualistic orientation $(\mathrm{M}=1.98, \mathrm{SD}=.99, \underline{\mathrm{n}}=43), \underline{\mathrm{t}}(86)=2.41, \underline{\mathrm{p}}<.01$. It is notable that respondents in both conditions provided cooperative assessments of the other party. The fact that the other party conceded and accepted the buyer's offer in all conditions might have influenced the participants to perceive the other party as cooperative.

\section{Hypothesis Tests}

In order to test the effect of social motive on negotiators' responses to a unilateral concession (Hypothesis 1), a 2 (partner's social motive) X 3 (concession timing) MANOVA was performed on negotiation perceptions (outcome and person) including both main and interaction effects. ${ }^{2}$ Multivariate results showed a main effect of social motive on negotiation perceptions, Wilks' Lambda $=.83, \mathrm{~F}(5,78)=3.27, \mathrm{p}<.01$. Hypothesis 1 was supported in that negotiators 
who believed the other party was cooperatively motivated rated the negotiation outcomes and partner more positively across all measures. An examination of the univariate results revealed that partner's social motive had a significant effect on satisfaction with outcome, $F(1,82)=9.11$, $\mathrm{p}<.01$, satisfaction with partner, $\mathrm{F}(1,82)=11.70, \mathrm{p}<.001$, and estimated quality of the object, $F(1,82)=4.03, p<.05$, but not for the estimated value of the object, $F(1,82)=0.77, p>.10$, and credibility of the seller, $\mathrm{F}(1,82)=0.05, \mathrm{p}>.10$ (see Table 1 for means and SDs).

Logit loglinear analysis was performed to test the effect of social motive on attribution making (Hypothesis 2). When told that the other party had a cooperative social motive, 23 participants out of 45 attributed the other party's unilateral concession to the other party's disposition. When they were told that the other party had an individualistic social motive, 9 participants out of 43 attributed the other party's concession making to the other party's disposition. The logit analysis showed that participants in the cooperative condition were 3.78 times more likely to attribute the other party's concession making to that party's disposition than were participants in the individualistic conditions (lambda $=1.33 ; e^{\lambda}=3.78$ ). Negotiators who thought the other party had an individualistic social motive were 2.27 times more likely to attribute to the lesser value of the object as compared with negotiators who thought the other party had a cooperative social motive, but this difference was not within the $95 \%$ confidence interval (lambda $=0.82 ; e^{\lambda}=2.27$ ). Therefore, Hypothesis 2 was partially supported.

In order to test Hypothesis 3, the interactions in the prior 2 (social motive) X 3 (concession timing) MANOVA were examined. As predicted in Hypothesis 3, the interaction of concession timing and social motive was significant, Wilks' Lambda $=.70, \underline{\mathrm{F}}(10,156)=3.00, \mathrm{p}$ $<.01$. More specifically, univariate tests showed that the interaction between concession timing and social motive had significant effects on satisfaction with the outcome, $\underline{\mathrm{F}}(2,82)=9.00, \underline{\mathrm{p}}<$ 
.001 , value estimation of the object, $\underline{\mathrm{F}}(2,82)=3.46, \underline{\mathrm{p}}<.05$, quality estimation of the object, $\underline{\mathrm{F}}(2,82)=2.72, \underline{\mathrm{p}}<.08$, and satisfaction with the negotiation partner, $\underline{\mathrm{F}}(2,82)=6.65, \underline{\mathrm{p}}<.01$, but not on credibility of the seller, $\underline{\mathrm{F}}(2,82)=.92, \underline{p}>.10$. To illustrate the interaction pattern, the satisfaction interactions are graphed in Figures 2 and 3. Figure 2 shows high satisfaction with the outcome in all conditions, except in the immediate concession with individualistic social motive condition where subjects were satisfied but less so. Figure 3 shows that subjects were highly satisfied with the partner in all conditions except when the partner was an individualistically oriented one who used immediate or delayed concessions.

One-way MANOVA was performed to examine the concession timing effect in more detail where the negotiation partner's social motive was individualistic. Multivariate results revealed that concession timing had significant effects on outcome and person perceptions $($ Wilks' Lambda $=.55, F(10,72)=2.49, \mathrm{p}<.05)$. Planned contrasts showed that the immediate concession caused lower satisfaction with the outcome, $\underline{\mathrm{t}}(40)=4.17, \underline{\mathrm{p}}<.001$, lower estimation of the object quality, $\underline{\mathrm{t}}(40)=2.63, \underline{\mathrm{p}}<.01$, lower evaluation of the object value, $\underline{\mathrm{t}}(40)=2.45, \underline{\mathrm{p}}<$ .01 , lower satisfaction with the negotiation partner, $\underline{\mathrm{t}}(40)=2.01, \underline{\mathrm{p}}<.05$, and lower credibility of the seller, $\underline{\mathrm{t}}(40)=2.14, \underline{\mathrm{p}}<.05$ (See Table 1 for means and SDs). Therefore, Hypothesis 3a was supported in that the concession timing effects were confirmed when the other party was believed to have individualistic social motives.

One-way MANOVA was conducted using only the cases where the negotiation partner's social motive was cooperative. Multivariate results showed that concession timing did not have significant effects on outcome and person perceptions, Wilks' Lambda $=.81, F(10,76)=0.86, p$ $>.10$ (See Table 1 for means and SDs). As expected in Hypothesis 3b, planned contrast tests, which compared immediate concession with other (gradual and delayed) concessions, did not 
reach statistical significance: satisfaction with the outcome, $\underline{t}(42)=-1.24, \underline{p}>.10$, estimation of the quality of the object, $\underline{t}(42)=-.19, \underline{p}>.10$, estimation of the value of the object, $\underline{t}(42)=-.31, \underline{p}$ $>.10$, satisfaction with the partner, $\underline{\mathrm{t}}(42)=-1.37, \underline{\mathrm{p}}>.10$, credibility of the seller, $\underline{\mathrm{t}}(42)=.41, \underline{\mathrm{p}}>$ .10. Therefore, the concession timing effects were not confirmed when the other party was believed to have cooperative social motives. This result completes the support for Hypothesis $3 \mathrm{~b}$.

\section{Discussion}

This study tested the concession timing effect when the negotiation partner was believed to have either an individualistic or cooperative social motive. The current study confirmed the concession timing effect (Kwon \& Weingart, 2004; Galinsky et. al., 2002) when the negotiation partner was believed to have an individualistic social motive. That is, when a negotiation partner made an immediate concession and was believed to be individualistically motivated, the focal negotiator was dissatisfied with the outcome and the negotiation partner. When the partner was expected to be cooperatively motivated, focal negotiators were as satisfied with partner and outcome as when the other party had made gradual or delayed concessions. The results imply that a negotiator's belief about the other party's social motive overrides the concession timing effect for unilateral concessions. Beliefs about social motives can come from a variety of sources, including the relationship between negotiators. Assuming negotiators expect a cooperative orientation from someone with whom they have a close or ongoing relationship, in a negotiation with a friend or family member, an individual may make an immediate concession with impunity. In other words, negotiators do not need to be tough in order to satisfy their negotiating partners in such situations.

When the negotiation partner was believed to have a cooperative social motive rather than an individualistic one, his or her concessionary behavior was more likely to be interpreted 
positively, even though the agreed-upon price was the same in the two conditions. This effect occurred primarily when concessions were immediate. When the other party made gradual concessions, a process that is normative for distributive negotiations, there was no difference in the effect of social motive on satisfaction with the outcome and the partner. It appears that in situations that are counter normative (e.g., immediate concessions), negotiators search for explanations for the other party's behavior. Information about the other party's social motive provided information with which to interpret the counter-normative behavior.

Negotiators used the information about the other party's social motive to formulate attributions for the other party's behavior. When a negotiator expected the other party to have a cooperative social motive rather than an individualistic one, the negotiator was more likely to attribute the other party's unilateral concession to his or her disposition. That is, "the other party conceded because s/he is a cooperative person". This was not the case for those who believed their partner was individualistic. Negotiators who thought the other party had individualistic social motive were most likely to attribute a unilateral concession to the lesser value of the object (13 of the 43 individualistic-expectation subjects did so), but they were only slightly more likely to attribute to the value of the object than were negotiators who believed their partners were cooperative.

Results suggest that an individual's script for negotiating with a cooperatively-oriented partner may differ from the script he or she would use for an individually-oriented partner (Halpern, 1996, 1997a). An immediate concession was consistent with the script for negotiating with a cooperatively-oriented person. In addition, when a negotiation partner was expected to have a cooperative social motive, then he or she was believed to be honest and trustworthy. Therefore, when a satisfactory agreement was reached, a negotiator did not feel the need to 
second-guess or monitor the other party in order to protect himself or herself from being exploited (Yamagishi, 1986).

The result of this study has a practical implication. When a person negotiates with a stranger in a distributive context, a gradual or delayed concession strategy is more effective than an immediate concession strategy in terms of social psychological aspects. The concession timing effect holds only when a negotiator fears exploitation. However, when the negotiator knows that the other party has a cooperative social motive (as in negotiations between family members, friends, or prior negotiating partners), a negotiator does not need to be tough in order to satisfy the other party and to create a perception of credibility. An immediate concessionmaking strategy is as effective as a gradual or delayed concession making strategy as long as the relationship between negotiators is cooperative.

The current study has some theoretical contributions. The phenomenon of doing better and feeling worse (Boles \& Messick, 1995; Medvec et al., 1995; Medvec \& Savitsky, 1997) when a negotiation partner makes an immediate concession (Galinsky et al., 2002; Kwon and Weingart, 2004) might not occur after negotiating with cooperatively oriented negotiation partner. That is, even when the negotiation partner makes an immediate concession, if perceived to be cooperatively oriented, negotiators tend not to be focused on the counterfactual thought, "I could have done better." Therefore, the negotiators will not experience dissatisfaction with the negotiated outcome and partner.

The findings of this study imply that a negotiator's belief about the other party's social motive may affect reactive devaluation, but only when concessions are immediate. When the negotiation partner is expected to be individualistically motivated, the negotiation partner's immediate concession, as compared with gradual or delayed concession, intensified the focal 
negotiator's devaluation of the object under negotiation (Kwon \& Weingart, 2004). However, this was not true when the negotiation partner was believed to be cooperatively motivated. That is, the buyer valued the car the same regardless of when the concession was made if they believed the seller was cooperatively motivated. Future research should examine the mechanisms through which expectations of social motives can override reactive devaluation.

It's interesting to note that the results held regardless of the focal negotiator's social motive. Perceptions of the other party's behavior was not influenced by whether the perceiver was cooperatively or individualistically oriented. It is possible that the information about the other party's social motive was considered a more reliable, dominant source of information to make attributions. Future research could test whether the own social motive would moderate the concession timing effect when information about the other party's motives are not available.

The current study addresses an underinvestigated area - how social motive expectations influence negotiator perceptions. Most studies on social value orientation have investigated the effect of the focal person's motivation on the negotiation process and its outcome (De Dreu et al, 2000). Only a few studies have investigated the effect of the focal negotiator's expectations regarding the social motive of the other party and most have focused on its effect on trust (De Dreu et al., 1998; Deutsch, 1960; Kee \& Knox, 1970; Loomis, 1959; Pruitt \& Kimmel, 1977; Van Kleef et al., 2005). In that expectations provide a lens through which experiences are interpreted, and these interpretations influence subsequent behavior, understanding the effects of social motive expectations becomes crucial. 


\section{References}

Abelson, R. P. (1981). Psychological status of the script concept. American Psychologist, 36, $715-729$.

Bazerman, M. H. (1983). Negotiator judgment. American Behavioral Scientist, 27, 211-228.

Bazerman, M. H., \& Samuelson, W. F. (1983). I won the auction, but don't want the prize. Journal of Conflict Resolution, 27, 618-634.

Boles, T. L., \& Messick, D. M. (1995). A reverse outcome bias: The influence of multiple reference points on the evaluation of outcomes and decisions. Organizational Behavior and Human Decision Processes, 6, 262-275.

Carnevale, P. J., \& Isen, A. (1986). The influence of positive affect and visual access on the discovery of integrative solutions in bilateral negotiation. Organizational Behavior and Human Decision Processes, 37, 1-13.

Curhan, J. R., Neale, M. A., \& Ross, L. (2004). Dynamic valuation: Preference changes in the context of face-to-face negotiation. Journal of Experimental Social Psychology, 40, 142151.

De Cremer, D., Snyder, M., \& Dewitte, S. (2001). "The less I trust, the less I contribute (or not)?" The effects of trust, accountability, and self-monitoring in social dilemmas. European Journal of Social Psychology, 31, 93-107.

De Dreu, C. K. W., Giebels, E., \& Van de Vliert, E. (1998). Social motives and trust in integrative negotiations: The disruptive effects of punitive capacity. Journal of Applied Psychology, 83, 408-422. 
De Dreu, C. K. W., Weingart, L. R., \& Kwon, S. (2000). Influence of social motives on integrative negotiation: A meta-analytic review and test of two theories. Journal of Personality and Social Psychology, 78, 889-905.

Deutsch, M. (1949). A theory of cooperation and competition. Human Relations, 2, 199-231.

Deutsch, M. (1960). The effect of motivational orientation upon trust and suspicion. Human Relations, 13, 123-139.

Deutsch, M. (1969). Conflicts: Productive and destructive. Journal of Social Issues, 25, 7-41.

Deutsch, M. 1973. The resolution of conflict: Constructive and destructive processes. New Haven: Yale University Press.

Fry, W., Firestone, I., \& Williams, D. (1983). Negotiation process and outcome of stranger dyads and dating couples: Do lovers lose? Basic and Applied Social Psychology, 4, 1-16.

Galinsky, A. D., Seiden, V. L., Kim, P. H., \& Medvec, V. H. (2002). The dissatisfaction of having your first offer accepted: The role of counterfactual thinking in negotiations. Personality and Social Psychology Bulletin, 28, 271-283.

Halpern, J. J. (1994). The effect of friendship on personal business transactions. Journal of Conflict Resolution, 38, 647-664.

Halpern, J. J. (1996). The effect of friendship on decisions: Field studies of real estate transactions. Human Relations, 49, 1519-1547.

Halpern, J. J. (1997a). Elements of a script for friendship in transactions. Journal of Conflict Resolution, 41, 835-868.

Halpern, J. J. (1997b). The transaction index: A method for standardizing comparisons of transaction characteristics across different context. Group Decision and Negotiation, 6, $557-572$. 
Hornstein, H. A. (1976). Cruelty and kindness: A new look at aggression and altruism. Englewood Cliffs, NJ: Prentice-Hall.

Isen, A. M. \& Levin, P. F. (1972). Effect of feeling good on helping: Cookies and kindness. Journal of Psychology, 21, 301-10.

Kee, H. W., \& Knox, R. E. (1970). Conceptual and methodological considerations in the study of trust and suspicion. Journal of Conflict Resolution, 14, 357-366.

Kelley, H. H., \& Stahelski, A. J. (1970). Social interaction basis of cooperators' and competitors' beliefs about others. Journal of Research in Personality, 9, 240-251.

Kuhlman, D. M., \&Wimberley, D. C. (1976). Expectations of choice behavior held by cooperators, competitors, and individualists across four classes of experimental games. Journal of Personality and Social Psychology, 34, 69-81.

Kwon, S. (2003). Is the information from an expert helpful? The concession timing effect and an expert's advice. International Journal of Negotiation, 8, 85-100.

Kwon, S. \& Weingart, L. R. (2004). Unilateral concessions from the other party: Concession behavior, Attributions, and Negotiation Judgments. Journal of Applied Psychology, 89, 263-278.

Lepper, M., Ross, L., Ward, A., \& Tsai, J. (2002). The grass is always greener: "Reactive devaluation" of proffered concessions. Unpublished manuscript, Stanford University, Stanford, CA.

Lewicki, R., J., Barry, R., Saunders, D. M., \& Minton, J. W. (2003). Negotiation. Boston: Irwin. Loomis, J. L. (1959). Communication, the development of trust, and cooperative behavior. Human Relations, 12, 305-315. 
Markman, K. D., Gavanski, I., Sherman, S. J., \& McMullen, M. N. (1993). The mental simulation of better and worse possible worlds. Journal of Experimental Social Psychology, 29, 87-109.

McClintock, C. G. (1978). Social values: Their definition, measurement, and development. Journal of Research and Development in Education, 12, 121-137.

Medvec, V. H., Madey, S., \& Gilovich, T. D. (1995). When less is more: Counterfactual thinking among Olympic medalists. Journal of Personality and Social Psychology, 69, 603-610.

Medvec, V. H., \& Savitsky, K. (1997). When doing better means feeling worse: The effects of categorical cutoff points on counterfactual thinking and satisfaction. Journal of Personality and Social Psychology, 72, 1284-1296.

Messick, D. M., \& McClintock, C. G. (1968). Motivational basis of choice in experimental games. Journal of Experimental Social Psychology, 4, 1-25.

Milgrom, P. \& Roberts, J. (1986). Prices and advertising signals of product quality. Journal of Political Economy, 94, 796-821.

Pruitt, D. G., \& Kimmel, M.J. (1977). Twenty years of experimental gaming: Critique, synthesis, and suggestions for the future. Annual Review of Psychology, 28, 363-392.

Pruitt, D. G., \& Rubin, J. Z. (1986). Social conflict: Escalation, stalemate, and settlement. New York: Random House.

Raiffa, H. (1982). The art and science of negotiation. Cambridge, MA: Harvard University Press.

Ross, L. (1995). Reactive devaluation in negotiation and conflict resolution. In K.J. Arrow, R.H. Mnookin, L. Ross, A. Tversky, \& R. Wilson (Eds.) Barriers to conflict resolution (pp. 26-42). New York: Norton. 
Ross, L., \& Stillinger, C. (1991). Barriers to conflict resolution. Negotiation Journal, 7, 389-404.

Schoeninger, D.W., \& Wood, W. D. (1969). Comparison of married and ad hoc mixed-sex dyads negotiating the division of a reward. Journal of Experimental Social Psychology, 25, 419427.

Thompson, L., Peterson, E., \& Kray, L. (1995). Social context in negotiation an informationprocessing perspective. In R.M. Kramer, \& D.M. Messick, (Eds.), Negotiation as a social Process (pp. 5-36). California: Sage.

Thompson, L., Valley, K. L., \& Kramer, R. M. (1995). The bittersweet feeling of success: An examination of social perception in negotiation. Journal of Experimental Social Psychology, 31, 467-492.

Tinsley, C. H., O’Connor, K. M., \& Sullivan, B. A. (2001). Tough guys finish last: The perils of a distributive reputation. Organizational Behavior and Human Decision Processes, 88, 621-642.

Van Kleef, G. A., De Dreu, C.K.W., \& Manstead, A. S. R. (2005, June). Supplication and appeasement in negotiations: The interpersonal effects of disappointment, worry, guilt, and regret. Paper presented at the meeting of the International Association for Conflict Management, Seville, Spain.

Van Lange: P. A. M., Otten, W., De Bruin, E. M. N., \& Joireman, J. A. (1997). Development of prosocial, individualistic, and competitive orientations: Theory and preliminary evidence. Journal of Personality and Social Psychology, 73, 733-746.

Weingart, L. R., Bennett, R. J., \& Brett, J. M. (1993). The impact of consideration of issues and motivational orientation on group negotiation processes and outcome. Journal of Applied Psychology, 78, 504-517. 
White, S. B., \& Neale, M. (1994). The role of negotiator aspirations and settlement expectancies on bargaining outcomes. Organizational Behavior and Human Decision Processes, 57, 91-108.

White, S. B., Valley, K. L., Bazerman, M. H., Neale, M. A., \& Peck, S. R. (1994). Alternative models of price behavior in dyadic negotiations: Market prices, reservation prices, and negotiator aspirations. Organizational Behavior and Human Decision Processes, 57, 430447.

Williamson, O. E. (1985). The economic institutions of capitalism: Firms, markets, relational capitalism. New York: Free Press.

Yamagishi, T. (1986). The provision of a sanctioning system as a public good. Journal of Personality and Social Psychology, 51, 110-116. 


\section{Footnotes}

${ }^{1}$ Note that in a single-issue negotiation, individualistic and competitive orientations are functionally the same because the only way to maximize own outcome (individualistic motivation) is at the other party's expense.

${ }^{2}$ The MANOVA was conducted with and without the buyer's social motive as a covariate. Buyer's social motive did not have a significant effect on outcome and person perception. In addition, it did not affect the relationship between the other independent variables and dependent variables. Therefore, buyer's social motive was not included in the results reported in this paper. 
Social Motive Expectations 29

Table 1

Means and Standard Deviations for Dependent Variables across Motivational Orientation and Concession Timing

\begin{tabular}{|c|c|c|c|c|c|}
\hline $\begin{array}{l}\text { Dependent } \\
\text { Variables }\end{array}$ & $\begin{array}{c}\text { Motivational } \\
\text { Orientation }\end{array}$ & $\begin{array}{c}\text { Concession } \\
\text { Timing }\end{array}$ & $\mathrm{n}$ & Mean & $\mathrm{SD}$ \\
\hline \multirow{6}{*}{$\begin{array}{l}\text { Satisfaction } \\
\text { with the } \\
\text { Outcome }\end{array}$} & \multirow{3}{*}{ Cooperative } & Immediate & 16 & 6.78 & .45 \\
\hline & & Gradual & 14 & 6.43 & .96 \\
\hline & & Delayed & 15 & 6.63 & .44 \\
\hline & \multirow{3}{*}{ Individualistic } & Immediate & 14 & 5.29 & 1.25 \\
\hline & & Gradual & 14 & 6.57 & .85 \\
\hline & & Delayed & 15 & 6.47 & .48 \\
\hline \multirow{6}{*}{$\begin{array}{l}\text { Estimated } \\
\text { Quality of the } \\
\text { Object }\end{array}$} & \multirow{3}{*}{ Cooperative } & Immediate & 16 & 4.78 & .60 \\
\hline & & Gradual & 14 & 4.71 & .61 \\
\hline & & Delayed & 15 & 4.77 & .86 \\
\hline & \multirow{3}{*}{ Individualistic } & Immediate & 14 & 3.96 & 1.08 \\
\hline & & Gradual & 14 & 4.82 & .72 \\
\hline & & Delayed & 15 & 4.50 & .57 \\
\hline \multirow{6}{*}{$\begin{array}{l}\text { Estimated } \\
\text { Value of the } \\
\text { Object }\end{array}$} & \multirow{3}{*}{ Cooperative } & Immediate & 16 & 10043.75 & 600.80 \\
\hline & & Gradual & 14 & 9946.43 & 777.19 \\
\hline & & Delayed & 15 & 10003.33 & 779.30 \\
\hline & \multirow{3}{*}{ Individualistic } & Immediate & 14 & 8946.43 & 2453.76 \\
\hline & & Gradual & 14 & 10502.86 & 790.64 \\
\hline & & Delayed & 15 & 9870.00 & 870.10 \\
\hline \multirow{6}{*}{$\begin{array}{l}\text { Satisfaction } \\
\text { with the } \\
\text { Partner }\end{array}$} & \multirow{3}{*}{ Cooperative } & Immediate & 16 & 6.56 & .54 \\
\hline & & Gradual & 14 & 6.04 & .69 \\
\hline & & Delayed & 15 & 6.50 & .82 \\
\hline & \multirow{3}{*}{ Individualistic } & Immediate & 14 & 5.25 & 1.42 \\
\hline & & Gradual & 14 & 6.36 & .72 \\
\hline & & Delayed & 15 & 5.53 & .93 \\
\hline \multirow{6}{*}{$\begin{array}{l}\text { Credibility of } \\
\text { the Seller }\end{array}$} & \multirow{3}{*}{ Cooperative } & Immediate & 16 & 4.91 & 1.05 \\
\hline & & Gradual & 14 & 5.18 & .93 \\
\hline & & Delayed & 15 & 4.93 & 1.44 \\
\hline & \multirow{3}{*}{ Individualistic } & Immediate & 14 & 4.36 & 1.38 \\
\hline & & Gradual & 14 & 5.32 & 1.09 \\
\hline & & Delayed & 15 & 5.17 & 1.33 \\
\hline
\end{tabular}




\section{Figure Caption}

Figure 1. A model of social motive and concession timing.

Figure 2. Interactive Effect of Concession Timing and Motivational Orientation on Satisfaction with Outcome.

Figure 3. Interactive Effect of Concession Timing and Motivational Orientation on Satisfaction with Partner 


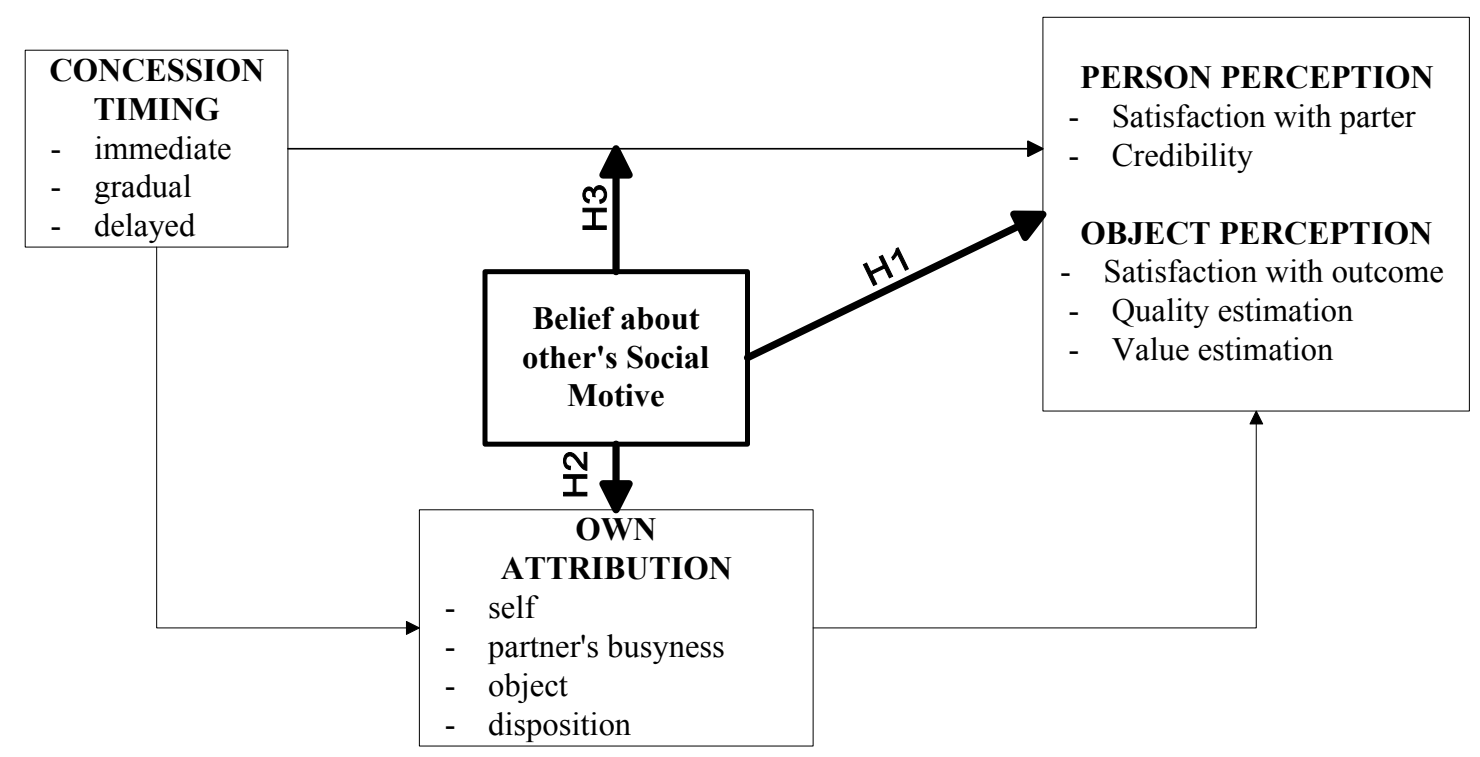


Social Motive Expectations 32

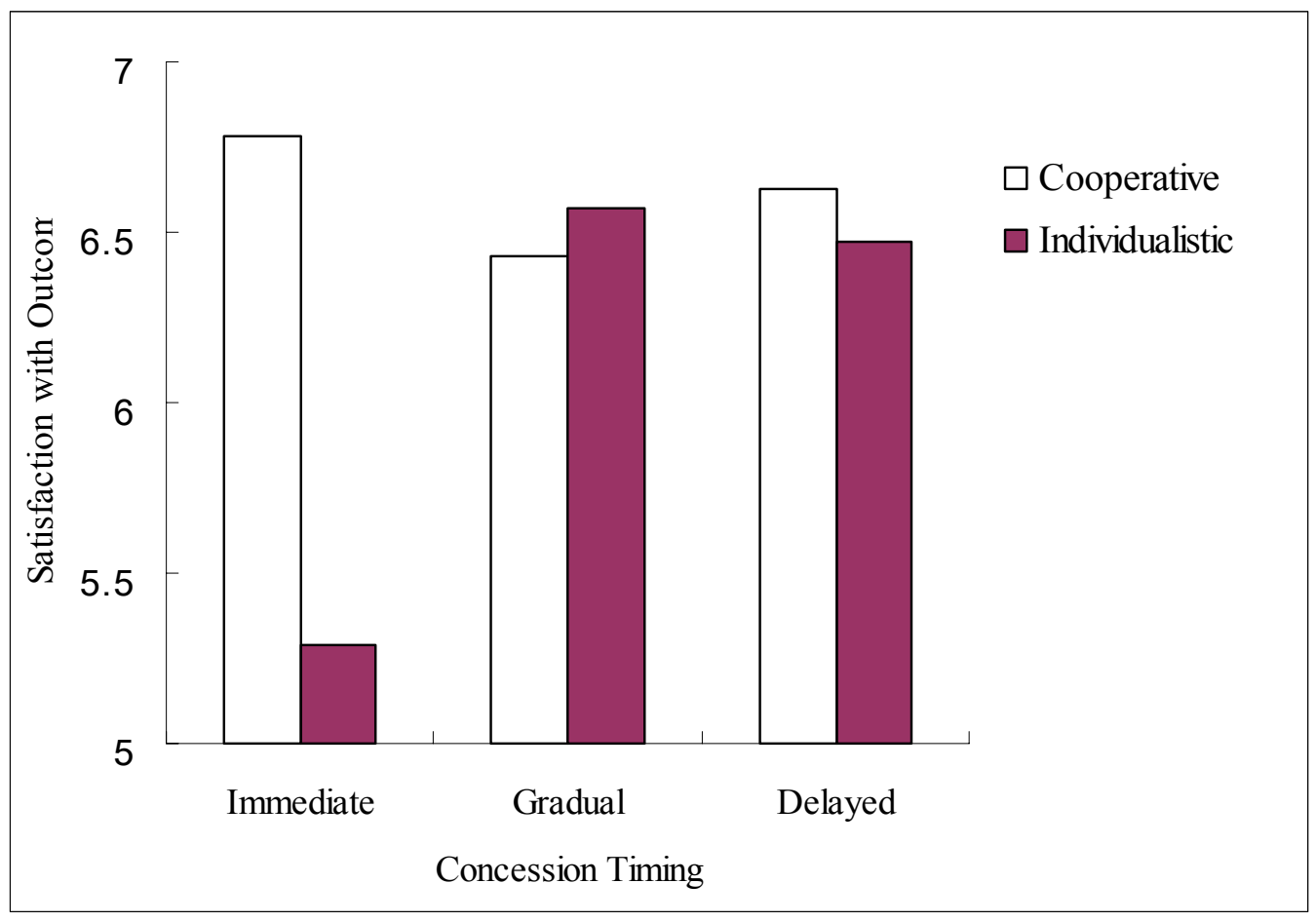


Social Motive Expectations 33

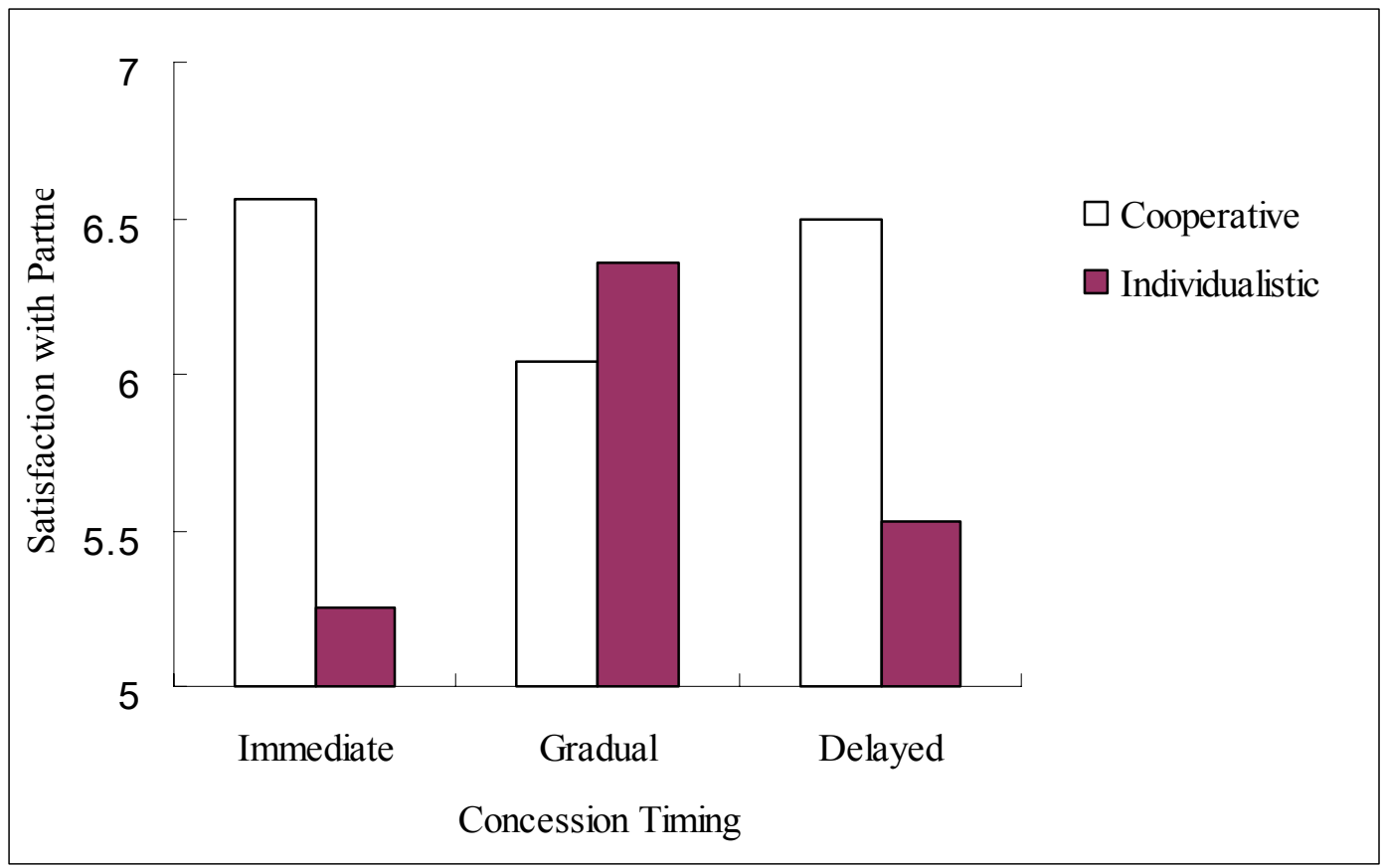

